1. Introduçäo;

2. Criação e implantação do Nutec;

3. Balanço das atividades realizadas; 4. Andlise da problemdica atual;

5. Conchusos.

\section{Criação e consolidação de um centro tecnológico no nordeste: a experiência do NUTEC}

Francisco Lopes Viana

Da UFC

\section{INTRODUÇĀO}

O desenvolvimento do tema que nos fora proposto apre sentar para os prezados participantes deste curso, ou seja, Criação e Consolidaçáo de um Centro Tecnológico no Nordeste, através da explicitaçıo da experiência viven ciada pelo Nutec, no estado do Ceara, ainda que no verdor da sua primeira infáncia, faz-nos depreender que o seu entendimento deva ser precedido de uma abordagem sucinta do processo de desenvolvimento global da regiăo nordestina.

O processo de desenvolvimento evidencia elevadas disparidades economicas e sociais com a regiso ControSul do país e indica que um elovado contingento da sua populaçáo vive no estado de pobreza absoluta, caracterizando, pois, o Nordeste como a mais extensa e populosa região subdesenvolvida do mundo ocidental.

Os instrumentos e mecanismos de políticas governamentais, até entz̃o implementados, têm se caracterizado como impotentes e insuficientes na resoluça dos complexos problemas com que nos defrontamos.

As causas do fenómeno de subdesenvolvimento cró. nico da regifo estăo, interiormente, associadas com os aspectos sociais, ecológicos e culturais que a diferenciam das demais regióes do País. Dentre os mecanismos a se- rem implementados na soluçío consciente de tais problemas, acreditamos, com base nas premissas adiante citadas, que a utilização da ciéncia e tecnologia, como estrategria para o desenvolvimento político, social, económico e cultural da regiao, possa ser um marco referencial importante, porquanto factível.

\subsection{Premissas baisicas}

- A base do desenvolvimento de qualquer regiao é a educaçáo em todos os níveis.

- No mundo modemo, nenhum país/estado/regiáo será desenvolvido se nato possuir uma base cultural forte e, sobretudo, uma base tecnologica.

- Qualquer alternativa de desenvolvimento só é real quando está voltada para resolver os problemas da população.

- Nós temos problemas próprios, que exigem soluçóes próprias. As experiências de outros povos podem ser aproveitadas, desde que não agridam nosso meio e nossa cultura.

- Cada sociedade tem uma cultura própria e a relação que o homem estabelece com o seu meio natural e especifica em cada povo.

No que se refere à problemática do desenvolvimento científico e tecnologico da regiao, identificamos como fundamental a sua inserção orgánica no esforço de desenvolvimento global, além de se proverem alteraçóes no quadro politico e institucional.

O Nutec, pois, surge dentro desse ambiente com uma mensagem de participaçio sistémica, procurando integrar o setor produtivo com a universidade, em cuja concepção orghinica e funcional prevalece a logica dos fins sobre os meios. Tal estratégia está orientada no sentido de analisar a realidade ecologica, cultural e Etnica, que identifica o nosso homem, procurando transformar os conhecimentos acumulados em instrumentos de ação para atuar sobre essa realidade, identificando os seus problemas e abrindo caminho d solugito dos mesmos.

\section{CRIAÇÃO E IMPLANTAÇÃO DO NUTEC}

O Núcleo de Tecnologia Industrial (Nutec) foi criado sob a forma de fundaçăo, com personalidade jurídica de direito privado, vinculada a Secretaria de Indústria e Comércio do estado do Ceará, cujo objetivo fundamental é o de prestar assistência tecnológica ao sistema produtivo e ao govemo.

\subsection{Pressupostos da implantaguto}

A institucionalização e implantação do núcleo foi fundamentada nos objetivos e diretrizes preconizados no Plano Diretor, elaborando no ano de 1978 , compreendendo as seguintes etapas:

a) diagnóstico do estágio tecnológico:

- cadastro das necessidades tecnologicas industriais (140 ompreses; 10 setores-atividades);

- cadistro de laboratório;

- cadastro de recursos humanos; 
b) determinação das linhas de ação:

- seleção dos setores e projetos prioritários;

- identificaçăo e objetivos dos programas;

e) estruturação orgânica e funcional;

d) plano de implantação.

O planejamento e a execução das atividades do Nutec foram inicialmente voltados para o desenvolvimento de pesquisas tecnologicas aplicadas, prestação de serviços técnicos ds empresas, ao poder público e à comunidade e, ainda, para a formação e o aperfeiçoamento de recursos humanos na área tecnológica.

\subsection{Modelo de atuação}

Procurando evitar duplicidade de estruturas e de labora. tórios, e ao mesmo tempo criar um sistema flexível de operação e atuação, planejou se a implementação de um fluxo de atuação sistematizada capaz de absorver as suas linhas de ação. Para tanto firmaram-se convênios com a Universidade Federal do Ceará, Universidade de Fortaleza e institutos de pesquisas e desenvolvimento de centros mais avançados, visando à utilização dos laboratórios e ao apoio e assessoramento aos projetos e programas do Nutec, como forma de promover a integraçăo universidade/governo/sistema produtivo.

Atualmente, o Nutec dispóe de uma infraestrutura mínima de laboratório, na área de química, alimentos $\mathrm{e}$ mineral, e de oficina de apoio técnico na área de eletroeletrônica, complementada pelos laboratórios em convênio com a Universidade Federal do Ceará, quais sejam: Laboratório de Ensaios de Materiais e Metrologia da UFC, Laboratório de Química Industrial da UFC, Laboratório de Tecnologia de Alimentos da UFC, Laboratório de Termodinâmica e Motores Térmicos da UFC/Nutec e Laboratório de Tecnologia Mecânica da UFC.

Tais laboratórios são utilizados para serviços de analises, testes, ensaios, controle de qualidade e pesquisa.
Figura 1

Fluxograma de atuação do Nutec

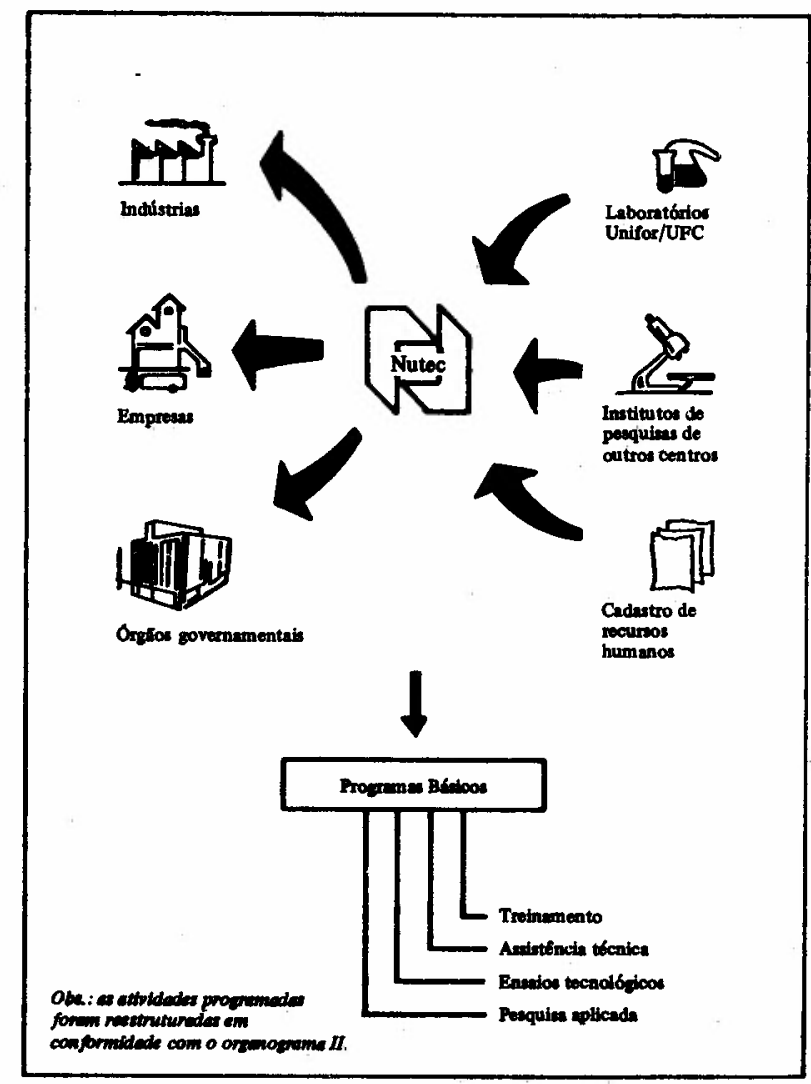

\subsection{Estrutura organizacional e funcional}

O Decreto-tei no 13.017, de 12 de dezembro de 1978, do governo do Ceará, instituiu o Núcleo de Tecnologia Industrial sob a forma de fundaçăo, com personalidade jurídica de direito privado, e aprovou o seu Estatuto e Regimento Interno, definindo para sua operacionalização o seguinte organograma matricial:

Figura 2

Organograma matricial do Nutec

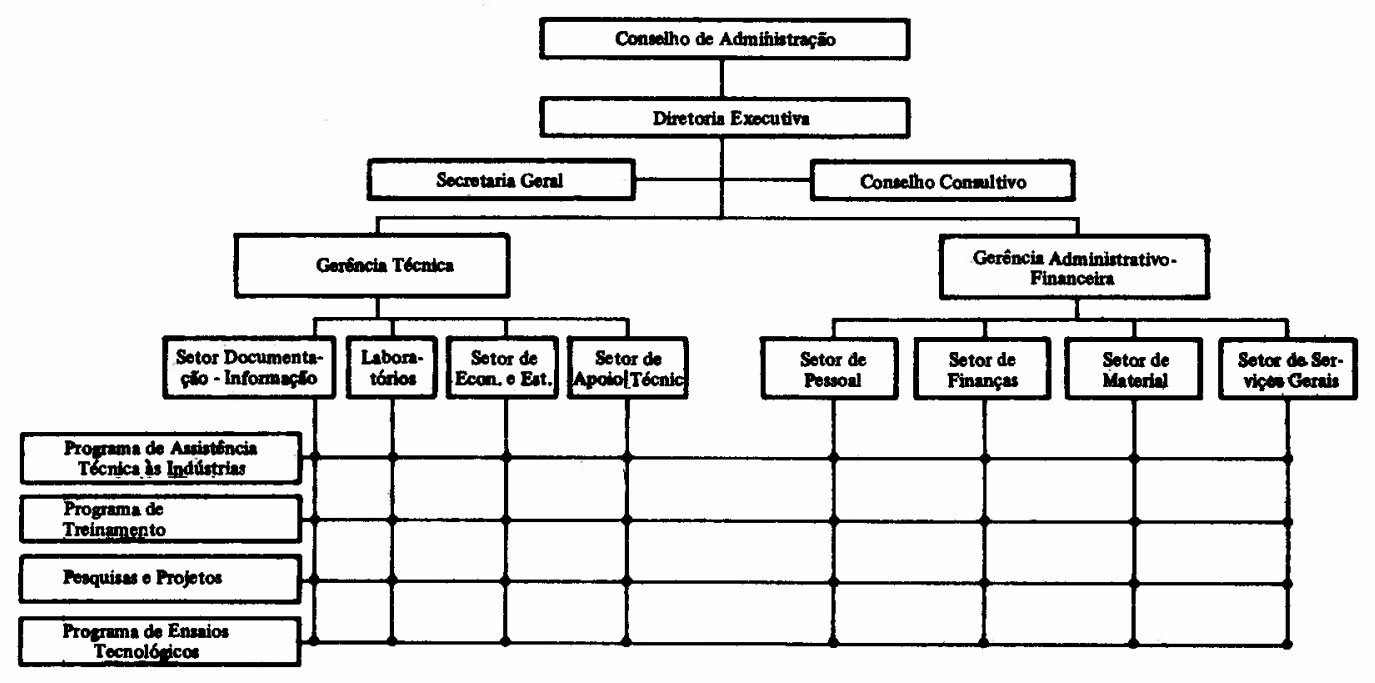




\section{BALANÇO DAS ATIVIDADES REALIZADAS}

A operacionalização das atividades do Nutec (Núcleo de Tecnologia Industrial) vem sendo desenvolvida de forma sistêmica, através de uma estrutura interdisciplinar de programas, projetos e serviços tecnológicos em apoio ao setor produtivo, empresas e órgáos governamentais, destacando-se, contudo, a participaç̃o de pessoal técnico do próprio Núcleo, professores das universidades em convênio e técnicos especialistas da comunidade identificados no Cadastro de Recursos Humanos.

\subsection{Atividades realizadas no periodo de marco de 1979 a dezembro de 1982}

Quadro 1

\begin{tabular}{|c|c|c|c|c|c|}
\hline Atividades & 1979 & 1980 & 1981 & 1982 & Total \\
\hline \multicolumn{6}{|l|}{$\begin{array}{l}\text { Programa de Assistência Técnica } \\
\text { Empresas assistidas através dos serviços }\end{array}$} \\
\hline $\begin{array}{l}\text { - Manutenção eletro-eletrônica } \\
\text { - Economia de energia } \\
\text { - Consultoria } \\
\text { - Projetos in dustriais } \\
\text { Projeto de Conversão de Velculos }\end{array}$ & 45 & 100 & 175 & 215 & $215^{*}$ \\
\hline $\begin{array}{l}\text { - número de retificas credenciadas } \\
\text { - número de veículos convertidos } \\
\text { Projetos especificos }\end{array}$ & $\begin{array}{l}1 \\
5\end{array}$ & $\begin{array}{r}10 \\
458\end{array}$ & $\begin{array}{r}13 \\
287\end{array}$ & $\overline{-}$ & $\begin{array}{r}24 \\
750\end{array}$ \\
\hline \multicolumn{6}{|l|}{$\begin{array}{l}\text { Programa de Ensaios Tecnológicos } \\
\text { Controle de aualidade - número de determinacőes }\end{array}$} \\
\hline $\begin{array}{l}\text { - Serviço de análises, testes, ensaios } \\
\text { nas áreas de: tecnologia de alimentos, química industrial, } \\
\text { mecânica e materiais, tecnologia mecânica }\end{array}$ & 261 & 4.517 & 7.570 & 7.998 & 20.346 \\
\hline \multicolumn{6}{|l|}{$\begin{array}{l}\text { Programa de Treinamento } \\
\text { Formaçāo de técnicos de nível médio } \\
\text { - Núcleo de Tecnologia de Calçados e Afins (NTCA) }\end{array}$} \\
\hline $\begin{array}{l}\text { - Número de técnicos formados } \\
\text { Capacitaçāo de recursos humanos (extensâo e reciclagem) }\end{array}$ & - & - & 30 & 30 & 60 \\
\hline $\begin{array}{l}\text { - Número de cursos realizados } \\
\text { - Número de participantes } \\
\text { - Treinamento pessoal do Nutec } \\
\text { - Estágios }\end{array}$ & $\begin{array}{r}5 \\
252 \\
9 \\
6\end{array}$ & $\begin{array}{r}9 \\
291 \\
11 \\
8\end{array}$ & $\begin{array}{r}6 \\
176 \\
12 \\
20\end{array}$ & $\begin{array}{r}4 \\
101 \\
16 \\
14\end{array}$ & $\begin{array}{r}24 \\
820 \\
48 \\
60\end{array}$ \\
\hline $\begin{array}{l}\text { Programa de Pesquisa A plicada } \\
\text { Pesquisas concluídas (perfis) } \\
\text { Desenvolvimento experimental }\end{array}$ & $\begin{array}{l}2 \\
3\end{array}$ & $\begin{array}{l}2 \\
3\end{array}$ & $\begin{array}{l}2 \\
4\end{array}$ & 18 & $\begin{array}{l}24 \\
10\end{array}$ \\
\hline
\end{tabular}

-215 diferentes empresas

\subsection{Recursos humanos}

Tabela 1

\begin{tabular}{lcccc}
\hline Discriminação & 1979 & 1980 & 1981 & 1982 \\
\hline $\begin{array}{l}\text { Pessoal do Nutec } \\
\text { Técnicos/professores } \\
\text { (Cadastro de Recursos }\end{array}$ & 41 & 58 & 71 & 125 \\
\begin{tabular}{l} 
Humanos) \\
\hline Total
\end{tabular} & 32 & 61 & 84 & 150 \\
\hline
\end{tabular}

\subsection{Recursos financeiros}

Tabela 2

\begin{tabular}{lrrrr}
\hline Discriminação & 1979 & 1980 & 1981 & 1982 \\
\hline $\begin{array}{l}\text { Recursos orçamentf́- } \\
\text { rios (estado) }\end{array}$ & 6.400 & 30.321 & 78.262 & 195.000 \\
$\begin{array}{l}\text { Recursos de projetos } \\
\text { de desenvolvimento }\end{array}$ & 10.880 & 25.840 & 37.759 & 135.000 \\
$\begin{array}{l}\text { Recursos próprios } \\
\text { (faturamento direto) }\end{array}$ & 890 & 7.000 & 20.000 & 56.000 \\
Total & 18.170 & 63.161 & 136.021 & 386.000 \\
\hline
\end{tabular}

Obs.: valores em Cr\$1.000.

\section{ANÁLISE DA PROBLEMATICA ATUAL}

A diretoria do Nutec, com base na experiencia vivenciada durante o seu primeiro mandato, explicitado no balanco das atividades realizadas no período de março de 1979 a março de 1982 , e procurando fortalecer e verticalizar as atividades a partir da reestruturação de alguns setores e programas, busca naturalmente adequar a estrutura intema da instituiçăo a preservação de suas funçסes básicas, bem como ampliar o seu campo de atuaçto nas atividades de extensáo tecnológica para o meio rural e d realizaçro de projetos especiais para o desenvolvimento industrial e tecnológico do estado do Ceará.

Tais mudanças, contudo, procuraram ampliar o campo de atuação do Nutec, dentro da mesma filosofia operacional. Destacamos, a seguir, as estratégias de desenvolvimento tecnológico, através dos projetos prioritários que estão sendo desenvolvidos pelo Nutec.

\subsection{Projeto de implantraño do Núčleo de Inovaç̃o Tecnolbgica}

Motes: 
a) levantar a oferta tecnologica existente no estado, com o objetivo de identificar as tecnologias geradas que são suscetíveis de serem transferidas;

b) mapear e identificar a demanda tecnológica do setor produtivo e organismos do governo, como forma de identificar as necessidades tecnologicas industriais para $o$ desenvolvimento de novos produtos e processos;

c) difundir, na comunidade técnico-científica, os mecanismos de proteção aos inventores, como também fomentar o exercício de inventos;

d) criar mecanismos de transferência de tecnologias para o.meio rural.

\section{Realização:}

a) levantamento da oferta tecnológica existente no estado e analise e caracterização das tecnologias geradas;

b) identificação da demanda tecnológica nos setores têxtil, metal-mecânico, alimentos e mineral, e articulação com outros NIT para solucionar as proposiçoes demandantes:

c) acompanhamento de processos de pedidos de privilégio e apoio técnico para fortalecer o processo de difusáo:

- quarenta patentes;

- participação em duas feiras;

- assessoria a Coelce na normatizaçao do processo de inovação ;

- programa com inventores em rádios e jornais;

- busca de patentes no Inpi / Wipo;

- participação em concurso de inventos com premiação de inventores (segundo lugar no Concurso nordestino de Inventores);

d) apoio na difusão dos perfis tecnológicos para o meio rural.

\subsection{Projeto de implantação e operacionalização do Sistema Estadual de Ciência e Tecnologia}

Metas:

a) elaboração do diagnóstico das atividades de ciência e tecnologia - estado do Ceará;

b) cadastramento das entidades que atuam em ciência $e$ tecnologia no estado do Ceará;

c) cadastramento de recursos humanos;

d) cadastramento de projetos / atividades;

e) elaboração do plano estadual de ciência e tecnologia.

\section{Realizações:}

a) elaboração do diagnóstico das atividades de ciência e tecnologia - estado do Ceará - setembro de 1982:

b) publicação do cadastro de entidades atuantes em ciên. cia e tecnologia no estado do Ceara, contendo os anexos de laboratorios, especialistas e projetos;

c) levantamento dos dados de recursos humanos;

d) levantamento dos projetos que estão sendo desenvolvidos no estado do Ceará; e) estruturação do I Plano Estadual de Desenvolvimento Científico e Tecnológico, destacando-se os segmentos estratégicos, táticos e operacionais - novembro de 1982;

f) implantação e operacionalização do Sistema Estadual de Dèsenvolvimento Cientifico e Tecnológico.

\subsection{Estratégias de desenvolvimento integrado}

Voltar as açбes do nosso potencial científico-tecnológico para:

Figura 3

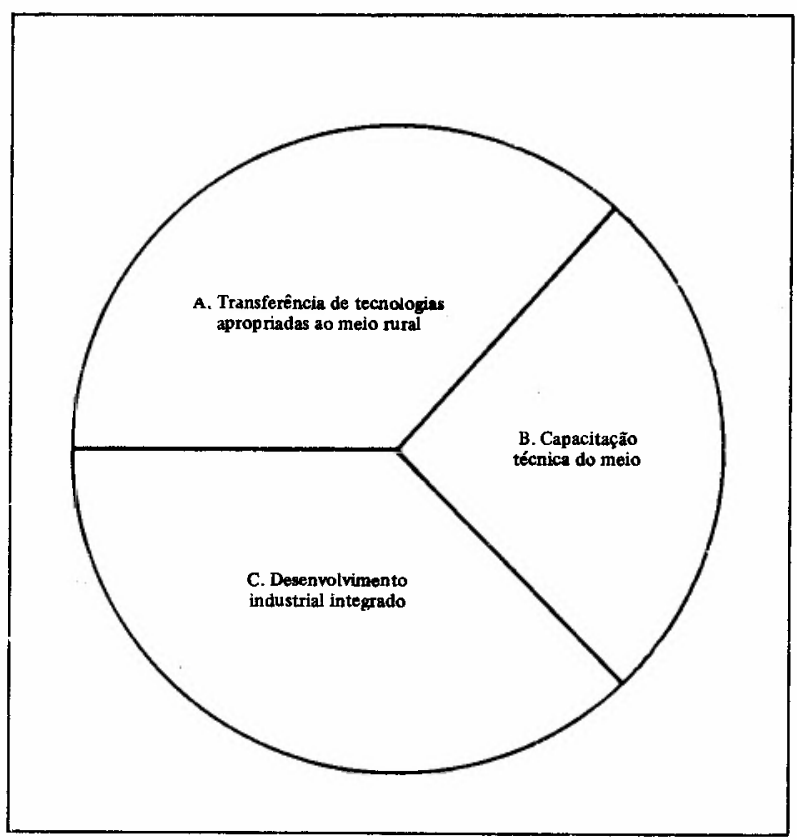

Pensar numa economia que leve em conta as pessoas, isto é, numa economia com base na produção pelas massas, em vez de produção em massa.

A. Transferência de tecnologias apropriadas ao meio rural

Tecnologias adequadas:

- desenvolvidas pelo Nutec/UFC;

- de fácil transferência;

- dentro de uma linguagem "Como fazer isso".

Disponíveis:

1. Batata chips.

2. Extrato de tomate.

3. Cajuina.

4. Maracujá (licor, geléia, néctar).

5. Vinagre.

6. Picles.

7. Jaca (creme e doce).

8. Molho de pimenta.

9. Mamão (néctar, compota, doce em massa).

10. Goiaba (doce, compota, polpa).

11. Banana passa.

12. Graviola (nectar).

13. Mandioca (amido, fécula, goma).

14. Panificação. 
15 - Caju (farinha do pedúnculo).

16. Sal refinado.

17. Fabricação de telhas e tijolos.

18. Aproveitamento dos resíduos de curtume (farinha, cola).

19. Fomo para produção de cal.

20. Microdestilaria (cana-de-açúcar).

21. Gasogenio para uso rural.

22. Dispositivo para proteção e religação automática.

Em desenvolvimento:

1. Granja de pequeno porte.

2. Laticínios.- queijo de leite de cabra.

3. Resíduos industriais para ração animal (abatedouros, peixes).

4. Catavento para bombear ou gerar eletricidade.

5. Aproveitamento integral da palha de carnaubeira.

6. Industrialização do LCC.

7. Secador solar para frutos tropicais.

8. Condicionador de ar solar.

9. Sinalização de passagem de nível.

10. Luz de emergência para sinalização.

11. Solo cal para habitação.

Projeto: Eletrificação e Industrialização do Meio Rural.

Objetivo: uso racional da energia e implantação de unidades industriais com base em tecnologias adequadas desenvolvidas pelo Nutec/UFC.

Figura 4

Estratégia de ação

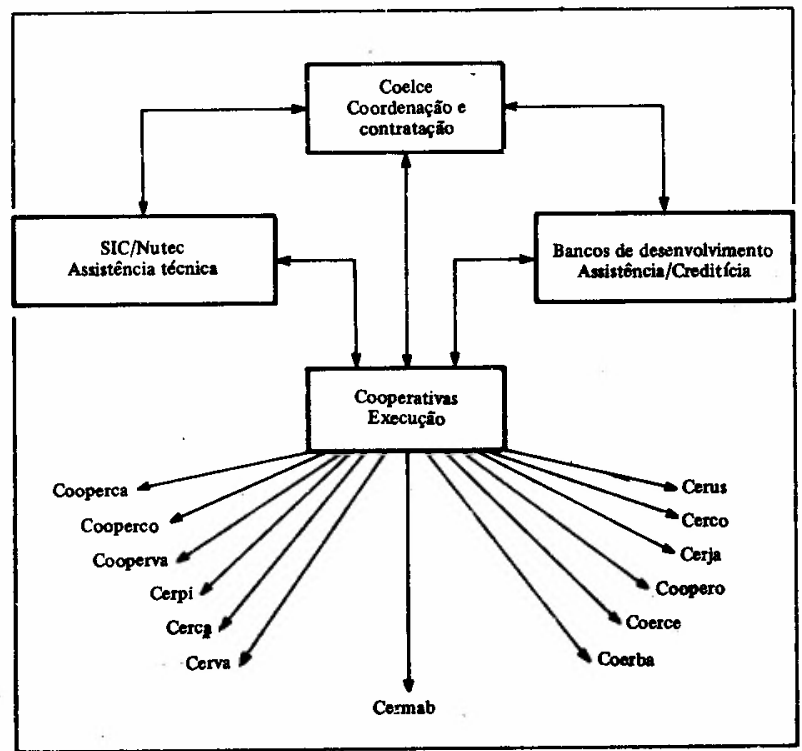

B. Capacitação técnica do meio

"A história e a experiência atual mostram ser o homem, e não a natureza, quem proporciona o primeiro recurso. E, com ele, a educação passa a ser o mais vital de todos os recursos."

Projeto: Universidade Técnica do Nível Médio.

"Um compromisso da sociedade para com a capacitação técnica do meio."
Objetivo: Aperfeiçoar o saber popular ou "juntar o que o povo já faz com o que o governo pode melhorar".

Quadro 2

Estratégia

\begin{tabular}{|c|c|c|}
\hline \multicolumn{3}{|c|}{ Universo } \\
\hline $\begin{array}{l}\text { Eletricista } \\
\text { Bombeiro } \\
\text { Soldador } \\
\text { Mestre-de-obras } \\
\text { Metalurgista }\end{array}$ & $\begin{array}{l}\text { Topógrafo } \\
\text { Mecânico } \\
\text { Técnico de saneamento } \\
\text { Lapidador } \\
\text { Laboratorista }\end{array}$ & $\begin{array}{l}\text { Eletrônico } \\
\text { Perfurador } \\
\text { Instrumentista } \\
\text { Ferreiro } \\
\text { etc. }\end{array}$ \\
\hline $\begin{array}{l}\text { Apoio financeiro } \\
\text { e logístico }\end{array}$ & & $\begin{array}{l}\text { Instrumentos } \\
\text { de ação }\end{array}$ \\
\hline $\begin{array}{l}\text { Coelce } \\
\text { Cagece } \\
\text { Ceminas } \\
\text { Cohab } \\
\text { Sosp } \\
\text { Daer } \\
\text { Fiec } \\
\text { etc }\end{array}$ & & $\begin{array}{l}\text { Pessoal e laboratórios } \\
\text { das universidades e es- } \\
\text { cola técnica } \\
\text { Equipes volantes de } \\
\text { treinamento }\end{array}$ \\
\hline
\end{tabular}

C. Estudo de desenvolvimento industrial integrado

Objetivo: identificar oportunidades industriais com base nos recursos naturais e em estudos de viabilidade técnico-econômica.

Quadro 3

Roteiro do estudo

\begin{tabular}{ll}
\hline Levantamento e avaliação & - Disponibilidade \\
dos recursos naturais & - Qualidade \\
& - Localização \\
& - Condiçães de acesso \\
Produtos que podem derivar & - Listar os principais produtos \\
desses recursos & - Interação com as indústrias \\
Perfil de mercado & existentes \\
dos produtos & - Balança comercial do estado \\
& - Mercado interno/externo \\
Avaliação técnico-econômica & - Matéria-prima \\
& - Processo \\
& - Utilização etc. \\
& - Infra-strutura \\
Análise e avaliação & Seleção da tecnologia e \\
de notas tecnológicas & descrição do processo \\
& - Capacidade de produção \\
& - Parâmetros econômicos
\end{tabular}

\section{CONCLUSÕES}

A análise do exposto nos itens anteriores leva-se a depreender que a não-existéncia de uma política explícita para o desenvolvimento científico e tecnológico a nível federal, regional e estadual, em estreita e orgânica conexão com a problemática do desenvolvimento político, social, economico e cultural da regiao, vem acarretando sérias distorçð̄es nas atividades das empresas, orgăos governamentais, técnicos e pesquisadores responsáveis pelo planejamento, execução e utilização da política do desenvolvimento cientifico e tecnológico.

Dentre as principais dificuldades com que se defrontam os institutos de pesquisa no Nordeste, na sua busca 
incansável de consolidar uma política de atuação, destacamos, com base na experiência vivenciada pelo Nutec, o seguinte:

a) dificuldades atuais a nivel global:

- observa-se que a sobrevivência das instituiçðes de pesquisa e desenvolvimento está intimamente ligada à capacidade de negociar projetos com órgãos financiadores:

- não existe uma política definida por parte dos órgãos financiadores, especificando prioridades por regiðes, a exemplo do sistema Embrapa;

- a não-garantia de recursos orçamentários federais e a dependência de recursos oriundos de projetos têm acarretado alta rotatividade de pessoal e dificuldades de contratação, dada a insegurança funcional que se oferece;

- o tempo decorrido entre a carta-consulta, entrada do projeto e aprovação - que nunca é inferior a seis meses - traz uma série de dificuldades como: definição e seleção de pessoal; dimensionamento real do projeto;

- a nãoexistência de um centro de documentação e informação, voltado para apoiar as pesquisas tecnológicas e o desenvolvimento dos centros de pesquisas, acarre ta: não-atualização do que se está fazendo; duplicidade de pesquisas; desconhecimento dos recursos humanos existentes nas diferentes áreas;

- casos ocorrem em que os centros de pesquisa e desenvolvimento que não tiveram seus projetos aprovados, sob argumento de que já foram desenvolvidos, não são informados dos resultados daqueles projetos;

- não existe transferência de resultados de centro para centro, mesmo que esses resultados interessem de imediato a determinado centro. Dada a necessidade de manutenção e sobrevivência, o que existe hoje são negociações de resultados;

- os centros de pesquisa e desenvolvimento estão sainda de sua área mais nobre para atuar nas áreas de engenharia e prestação de serviços;

- falta uma padronização de formulários de projetos por parte dos órgãos financiadores, bem como uma definição maior para os critérios de análise e avaliação dos projetos propostos;

b) Identificação dos principais problemas a nível estadual:

- inexistência, nos planos de desenvolvimento federal e estadual, de instrumentos eficazes para planificação, coordenação e acompanhamento das atividades de ciência e tecnologia, como uma estratégia para compatibilizar a capacitação técnico-científica com as necessidades maiores para o desenvolvimento global do estado do Ceará;

- limitado conhecimento das potencialidades físicas do estado, através de zoneamentos agrícola, industrial e mineral, como forma de viabilizar a exploração adequada dos recursos existentes, com uso racional de tecnologias apropriadas;

- desarticulação entre as entidades de execução e fomento das atividades científicas e tecnológicas no estado, ocasionando, ao mesmo tempo, escassez e desperdício de recursos materiais e humanos;

- inexistência de orçamento-programa para o segmento de ciência e tecnologia nos planos e programas governamentais, como forma de incentivar e disciplinar a execução das atividades de pesquisa e desenvolvimento ao nivel dos órgãos setoriais do governo;

- Jimitada participação da comunidade técnico-científica nas atividades políticas e culturais do estado, como forma de se permitir maior conhecimento e comprometimento com os problemas sócio-econômicos da região;

- inexistência no estado do Ceará de um plano de desenvolvimento científico e tecnológico que explique de forma sistêmica as políticas e diretrizes operacionais do Sistema Estadual de Ciência e Tecnologia, a partir da prioridade às atividades setoriais;

- Inadequada composição do Conselho Estadual de Ciência e Tecnologia (CECT), cuja participação está limitada aos órgãos do governo estadual, constante do Sistema Estadual de Planejamento, bem como limitação nas atribuiçбes da sua Secretaria Executiva;

- Inexistência, na Secretaria Executiva do CECT, de instrumentos básicos para planejamento, coordenação e acompanhamento de projetos de pesquisa e desenvolvimento a partir da geração e disseminação de informaçбes factuais de ciência e tecnologia, políticas de incentivos à utilização de tecnologia pelo setor produtivo e fomento de projetos financiados por fundo de desenvolvimento próprio;

- baixa utilização do potencial de recursos humanos, laboratoriais e equipamentos de apoio técnico existentes nas diversas entidades públicas e privadas que compõem - Sistema Estadual de Ciência e Tecnologia;

- utilização inadequada dos escassos recursos financeiros aplicados no desenvolvimento científico e tecnológico, em virtude da nãoespecificidade das linhas de atuação de pesquisa e desenvolvimento, tanto a nivel orçamentário, como, preferencialmente, nos programas e projetos especiais de desenvolvimento;

- inexistência de um processo de formação e especialização dos recursos humanos, tanto em nível superior, quanto em nível médio técnico, voltados para a resolução dos problemas maiores do estado do Ceará;

- inexistência do programa de pesquisa e desenvolvimento que esteja voltado, especialmente, para a utilização dos nossos recursos humanos e materiais, através da compatibilização dos projetos com as necessidades maiores do estado. 